\title{
Parameters predicting for prostate specific antigen response rates at one year post low-dose-rate intraoperative prostate brachytherapy
}

\author{
Kevin Martell, MD',2, Tyler Meyer, PhD 2,3, Michael Sia, MD', , Steve Angyalfi, MD',2, Siraj Husain, MD',2 \\ 'Division of Radiation Oncology, Tom Baker Cancer Centre, Calgary, Alberta, ${ }^{2}$ Department of Oncology, University of Calgary, Calgary, \\ Alberta, ${ }^{3}$ Division of Medical Physics, Tom Baker Cancer Centre, Calgary, Alberta, ${ }^{4}$ Department of Oncology, University of British Columbia. \\ Abbortsford, British Columbia, Canada
}

\begin{abstract}
Purpose: To develop a model for prostate specific antigen (PSA) values at one year among patients treated with intraoperatively planned ${ }^{125} \mathrm{I}$ prostate brachytherapy (IOPB).

Material and methods: Four hundred and deven patients treated with IOPB for prostate adenocarcinoma were divided into four groups: those with PSA values $\geq 3 \mathrm{ng} / \mathrm{ml} ;<3$ and $\geq 2 ;<2$ and $\geq 1$ or PSA $<1$ between 10.5 and 14.5 months post implantation (1yPSA). Ordinal regression analysis was then performed between patient, tumor, and treatment characteristics. 1yPSA values were also compared with toxicity outcomes.

Results: Median 1yPSA was 0.77 (0.04-17.36). Thirty-two patients $(8 \%)$ had a PSA $\geq 3 ; 35(9 \%)$ had PSA $<3, \geq 2$; $87(21 \%)$ had PSA $<2, \geq 1$, and most patients $254(62 \%)$ had PSA $<1$. PSA response was independent of gland volume, Gleason score, clinical stage, seed activity, $\mathrm{V}_{90}, \mathrm{~V}_{200}, \mathrm{D}_{90}$, or number of needles and seeds used. Older patients had significantly lower 1yPSA; median ages 65.1 (46.5-81.0), 62.1 (50.4-79.5), 60.5 (47.1-80.3), and 58.1 (45.1-74.2) years for each of the 1yPSA groups respectively $(p<0.001)$. Also, both implant $\mathrm{V}_{150}(p<0.001)$ and initial PSA values $(p=0.04)$ were predictive of 1yPSA values. There was no correlation between 1yPSA values and toxicity encountered.

Conclusions: PSA response at 1 year post IOPB appears to be dependent on patient age, initial PSA, and implant $\mathrm{V}_{150}$. Our results provide reassurance that parameters other than biochemical failure influence 1yPSA values.

Key words: brachytherapy, LDR, prostate cancer, PSA, seeds.

\section{Purpose}

Low-dose-rate brachytherapy is an effective, low-morbidity treatment for low to intermediate risk prostate cancer $[1,2,3,4,5]$. Although considerable effort has been made to predict 5-year biochemical relapse and disease free survival [6,7], immediate post treatment monitoring has been debated $[8,9,10]$. Because of this, patients are typically counseled that prognosis is dependent on Gleason score, clinical stage, and pre-treatment prostate-specific antigen (PSA). Because post-implant measurements of PSA are widely variable [11], they are currently not considered indicative of response to therapy until after approximately 2 years. However, even after this time, PSA bounce phenomena occurs and further complicates post implant PSA interpretation $[11,12,13]$. This prevents physicians and patients from evaluating treatment efficacy usually until several years post implantation, and for some patients, the uncertainty in PSA monitoring post brachytherapy makes other treatments such as prostatectomy more desirable.
Unfortunately, the lack of clinical interpretation of PSA values in the immediate months following brachytherapy has led to non-standardized monitoring during this time period. High PSA values are commonly disregarded. Furthermore, some patients do not have PSA levels drawn in the first year post treatment. However, it has been shown that decreases in PSA as early as 12 months post implantation are associated with improved long-term survival $[9,14,15]$. Therefore, we sought to identify normal PSA response at 1 year post implantation.

\section{Material and methods \\ Study population}

Between June 2003 and July 2014, 870 consecutive patients were treated at a single institution using intra-operatively planned ${ }^{125} \mathrm{I}$ based brachytherapy (IOPB). Eligible patients had biopsy proven prostate cancer and had either low risk disease defined by PSA $<10 \mathrm{ng} / \mathrm{ml}$ at baseline, 
Gleason score $<7$, and clinical stage $<\mathrm{T} 2 \mathrm{~b}$, or low-tier intermediate-risk disease defined by one intermediate risk factor of PSA $10-20 \mathrm{ng} / \mathrm{ml}$, Gleason Score $=7$, or clinical stage $\geq \mathrm{T} 2 \mathrm{~b}$. For the purposes of this analysis, patients without at least one PSA measurement made between 10.5 and 14.5 months post treatment (410) were excluded. Of the remaining 460 patients, 53 patients who received hormone therapy were excluded leaving a primary study population of 407 patients.

\section{Treatment characteristics}

Patients were treated with permanent ${ }^{125} \mathrm{I}$ seed $(\mathrm{Nu}-$ cletron SelectSeed, Elekta Brachytherapy, Stockholm, Sweden) implantation using an intraoperative technique, which is described in detail elsewhere [16,17]. In summary, at initial consultation patient prostate gland volume from the time of biopsy is reviewed. For large prostate glands, a computed tomography (CT) volume assessment is performed to confirm the volume. Patients with prostates

Table 1. Patient cohort, treatment, and outcomes characteristics, $N=407$. Medians (range) are reported unless otherwise specified

\begin{tabular}{|c|c|}
\hline Age (years) & $63.3(45.1-79.5)$ \\
\hline Pre-treatment PSA (ng/ml) & $5.8(0.3-13.8)$ \\
\hline Clinical stage No. (\%) & $\begin{array}{c}\text { T1a : } 3(1) \\
\text { T1b : } 1(0) \\
\text { T1c : } 310(78) \\
\text { T2a : } 71(18) \\
\text { T2b : } 9(2) \\
\text { T2c : } 2(1) \\
\text { Missing: } 11(\mathrm{~N} / \mathrm{A})\end{array}$ \\
\hline Gleason score No. $(\%)^{*}$ & $\begin{array}{c}3+3: 300(74) \\
3+4: 91(22) \\
4+3: 16(4)\end{array}$ \\
\hline AUA & $6(0-25)$ \\
\hline Number of cores positive on biopsy & $3(1-11)$ \\
\hline Number of cores biopsied & $10(3-17)$ \\
\hline Percentage positive biopsy tissue & $5(0.5-50)$ \\
\hline Seed activity (mCi) & $0.437(0.343-0.481)$ \\
\hline Gland volume (cc) & $33.9(13.2-60.5)$ \\
\hline Implant $D_{90}(G y)$ & $190(137.5-202.0)$ \\
\hline Implant $\mathrm{V}_{100}(\%)$ & $99.0(94.8-100.0)$ \\
\hline Implant $\mathrm{V}_{150}(\%)$ & $76.6(67.1-97.8)$ \\
\hline Implant $\mathrm{V}_{200}(\%)$ & $41.5(27.2-75.9)$ \\
\hline Needles used No. (\%) & $26(19-77)$ \\
\hline Seeds used No. (\%) & $72(41-99)$ \\
\hline Spacers used No. (\%) & $75(22-107)$ \\
\hline \multicolumn{2}{|c|}{$\begin{array}{l}\text { *One patient with Gleason } 3+2 \text { was treated and included in this cohort } \\
\text { PSA - prostate specific antigen, AUA - American Urologic Association symptom } \\
\text { score, } D_{90} \text { - dose received by } 90 \% \text { of the prostate volume, } V_{100}(\%) \text { - volume } \\
\text { of prostate receiving } 100 \% \text { of the prescribed dose, } V_{150}(\%)-\text { percentage of } \\
\text { prostate volume receiving } 150 \% \text { of the prescribed dose, } V_{200}(\%) \text { - percentage } \\
\text { of prostate volume receiving } 200 \% \text { of the prescribed dose }\end{array}$} \\
\hline
\end{tabular}

$>50 \mathrm{cc}$ are then offered hormone treatment prior to brachytherapy to shrink the prostate. Patients return to our cancer center on the day of their scheduled treatment for both planning and implantation of ${ }^{125}$ I seeds.

In the operating room, patients are placed under general or spinal anesthetic, and an intraoperative 3D reconstruction of the prostate is created using a mechanized ultrasound probe and the Nucletron FIRST system (Elekta Brachytherapy, Stockholm, Sweden). A planning target volume (PTV) that includes the prostate volume with a $1 \mathrm{~cm}$ radial margin $(0.5 \mathrm{~cm}$ posteriorly), rectum, and urethra are contoured, and plans with the following dose prescription and constraints are developed: prescribed dose to PTV of $144 \mathrm{~Gy}$; prostate $\mathrm{D}_{90}$ of $180-200 \mathrm{~Gy}, \mathrm{~V}_{100}>96 \%$, $\mathrm{V}_{150}$ of $74-85 \%, \mathrm{~V}_{200}$ of $37-48 \%$; urethral $\mathrm{V}_{140}<24 \%$, urethral $V_{150}<3 \%$, urethral $V_{160}$ of $0-1 \%$ and $<0.3$ cc of rectum receiving $100 \%$ of the prescribed dose $\left(D_{90}\right.$ refers to dose received by $90 \%$ of the structure and VYY is volume of the structure in \% receiving $Y \%$ of the prescribed dose). During planning, all seeds are placed within the prostate and no seeds are placed in the PTV margin outside the prostate. After the plans are completed, needle configurations of seeds and spacers are built by the system starting with the base plane needles. Seeds are then delivered through each needle using the SPOT PRO planning system (Elekta Brachytherapy, Stockholm, Sweden). Post treatment fluoroscopic images of the prostate are obtained and manual counts are made to ensure all seeds were delivered within the prostate volume. Over the study period there has been no change to dosimetric prescriptions, technique or brachytherapy inclusion criterion in this cohort although there was a tendency to treat more low tier intermediate risk patients in the last 5 years.

\section{Data collection}

Follow-up care for these patients included clinical assessments at one and three months post implantation and subsequent follow-ups annually thereafter. Data for all patients treated with brachytherapy at our center were entered into the database prospectively, as approved by our institutional research ethics board. Those patients travelling large distances to receive treatment were discharged early from clinic. PSA values were then monitored by their general practitioners and captured in the database through internal review of their electronic health record, which was available for all patients from the province of Alberta, Canada.

\section{Statistical methods}

Shapiro-Wilk test of normality were used to confirm non-normally distributed variables and descriptive statistics were used to characterize the cohort. Patients were then divided into four treatment response groups: those patients with a PSA value at 10.5-14.5 months (1yPSA) of $\geq 3$; $<3$ and $\geq 2 ;<2$ and $\geq 1$; and those with PSA $<1$. Inside treatment groups, pre-treatment, post-treatment, and intra-operative patient characteristics were reviewed and reported as medians plus ranges for continuous variables and frequencies plus percentages for ordinal variables. Ordinal regression analysis was performed between the 
response groups, and variables with two sided $p$-values $<0.05$ were accepted for inclusion in the final model. In this model, age and dosimetry parameters were treated as continuous variables. PSA response grouping was treated as a categorical variable. The model followed the Gumbel minimum value distribution: $P\left(Y \leq y\left[x_{i j}\right]\right) \sim 1-e^{-e^{\beta_{0}+\beta_{1} X_{1 j}+\cdots}}$. After model validation, the linear predictor was used to generate cumulative probability cross sections of the treatment response groupings for each statistically significant variable. Comparisons were also made between 1yPSA (PSA between 10.5 and 14.5 months post implantation) values, and urinary toxicity status of the patients between 5.5 and 18.5 months post treatment using the Mann-Whitney-Wilcoxon test. All data was analyzed using the R-programming language version 3.1.1 (www.r-project.org).

\section{Results}

Patient and treatment characteristics are summarized in Table 1. A total of 407 patients were included in this analysis. No patient had a PSA value measured less than 3 months after a procedure or catheterization. For this cohort, the median age was 63 (45-81) years, and median pre-treatment PSA value was $5.82(0.34-13.8) \mathrm{ng} / \mathrm{ml}$.
Median volume at the time of implantation was $33.9 \mathrm{cc}$ (13.2-60.5 cc). Most patients had clinical T1 disease (79\%) as opposed to T2 (21\%). 74\% of patients were Gleason 6 and $26 \%$ were Gleason 7 . Also, median percent of biopsy tissue positive was $5.0 \%(0.5-60 \%)$. Source activity ranged from 0.343 to $0.481 \mathrm{mCi}$ with a median of $0.437 \mathrm{mCi}$. Median intraoperative prostate $\mathrm{D}_{90}$ was 190.0 (137.5202.0) Gy. Only 9 patients had $D_{90}<175$ Gy. Median values for $\mathrm{V}_{100}, \mathrm{~V}_{150}$, and $\mathrm{V}_{200}$ were $98.9 \%, 76.6 \%$, and $41.4 \%$, respectively. A median of 72 seeds (41-99) in 26 (19-77) needles were used. 1yPSA nadirs ranged from 0.04 to 17.36 (median 0.76 ). No death out of a total of 15 deaths in this cohort was related to prostate cancer. On subsequent follow-up, a total of 12 (2.9\%) patients received treatment for biochemical recurrence. A further 21 (5.2\%) had PSA bounces of $>2.0$ above any previously measured value, and hence met the "Phoenix" definition of biochemical failure after a median follow-up of 3.4 (0.9-9.4) years [18].

Upon division of patients into ordinal groupings, older age, lower pre-treatment PSA, and lower implant $\mathrm{V}_{150}$ were associated with lower PSA at 1 year. For patients with 1yPSA values $<1.0, \geq 1.0$ and $<2.0, \geq 2.0$ and $<3.0$ or $\geq 3.0 \mathrm{ng} / \mathrm{ml}$ median ages were $65.1,62.1,60.5$, and 58.1 years; median pre-treatment PSAs were 5.8, 6.2, 5.5 and

Table 2. Pre-operative and intra-operative patient characteristics for prostate specific antigen response groupings measured between 10.4-14.5 months (prostate specific antigen value less than 1.0, $\geq 1.0$ and $<2.0$, $\geq 2.0$ and $<3.0$, or $\geq 3.0 \mathrm{ng} / \mathrm{ml}$ ). Values are reported as medians (range) unless otherwise specified

\begin{tabular}{|c|c|c|c|c|}
\hline & $\begin{array}{c}1 \mathrm{yPSA}<1.0 \mathrm{ng} / \mathrm{ml} \\
(n=253)\end{array}$ & $\begin{array}{c}1 y P S A \geq 1.0 \text { and }<2.0 \mathrm{ng} / \mathrm{ml} \\
(n=87)\end{array}$ & $\begin{array}{c}1 \mathrm{yPSA} \geq 2.0 \text { and }<3.0 \mathrm{ng} / \mathrm{ml} \\
(n=35)\end{array}$ & $\begin{array}{c}1 \mathrm{yPSA} \geq 3.0 \mathrm{ng} / \mathrm{ml} \\
(n=32)\end{array}$ \\
\hline $\begin{array}{l}\text { Age at time of implant } \\
\text { (years) }\end{array}$ & $65.1(46.5-81.0)^{b}$ & $62.1(50.4-79.5)^{b}$ & $60.5(47.1-80.3)^{b}$ & $58.1(45.1-74.2)^{b}$ \\
\hline $\begin{array}{l}\text { Median pre-treatment } \\
\text { PSA }(\mathrm{ng} / \mathrm{ml})\end{array}$ & $5.8(0.3-11.7)^{b}$ & $6.2(1.9-13.8)^{b}$ & $5.5(1.1-10.7)^{b}$ & $6.1(2.3-13)^{b}$ \\
\hline Clinical stage No. (\%) & $\begin{array}{l}\text { T1: } 195(76.8 \%) \\
\text { T2: } 52(20.5 \%)\end{array}$ & $\begin{array}{l}\text { T1: } 68(78.1 \%) \\
\text { T2: } 16(18.3 \%) \\
\end{array}$ & $\begin{array}{l}\text { T1: } 26(74.3 \%) \\
\text { T2: } 8(22.9 \%)\end{array}$ & $\begin{array}{l}\text { T1: } 25(78.1 \%) \\
\text { T2: } 6(18.7 \%)\end{array}$ \\
\hline Gleason score No. (\%) & $\begin{array}{c}3+3: 185(72.8 \%) \\
3+4: 57(22.4 \%) \\
4+3: 12(4.7 \%)\end{array}$ & $\begin{array}{c}3+3: 64(73.6 \%) \\
3+4: 19(21.8 \%) \\
4+3: 3(3.4 \%) \\
\end{array}$ & $\begin{array}{c}3+3: 27(77.1 \%) \\
3+4: 8(22.9 \%) \\
4+3: 0(0.0 \%)\end{array}$ & $\begin{array}{c}3+3: 24(75.0 \%) \\
3+4: 7(21.9 \%) \\
4+3: 1(3.1 \%) \\
\end{array}$ \\
\hline $\begin{array}{l}\text { Percentage of biopsy } \\
\text { tissue with cancer (\%) }\end{array}$ & $6.0(0.05-60.0)$ & $4.2(0.5-42.0)$ & $4.0(0.5-20.5)$ & $5.0(0.5-26.0)$ \\
\hline $\begin{array}{l}\text { Time from biopsy to } \\
\text { implant (months) }\end{array}$ & $5.5(0.3-70.2)$ & $5.3(2.3-41.2)$ & $5.2(2.5-20.2)$ & $6.4(2.9-22.9)$ \\
\hline $\begin{array}{l}\text { Prostate volume at } \\
\text { time of implant (cc) }\end{array}$ & $32.6(13.2-58.6)$ & $34.4(19.1-60.5)$ & $35.1(24.4-55.0)$ & $35.0(24.4-51.7)$ \\
\hline Source activity (mCi) & $0.437(0.343-0.481)$ & $0.437(0.343-0.481)$ & $0.437(0.410-0.481)$ & $0.437(0.403-0.461)$ \\
\hline$D_{90}(G y)$ & $189.2(137.5-201.5)$ & $191.3(176.2-202.0)$ & 187.8 (174.9-199.7) & 191.7 (181.0-201.1) \\
\hline $\mathrm{V}_{100}(\%)$ & $98.8(94.8-100.0)$ & $99.3(95.8-100.0)$ & $98.8(95.75-100.0)$ & $99.4(96.7-100.0)$ \\
\hline $\mathrm{V}_{150}(\%)$ & $76.2(67.1-97.8)^{a}$ & $77.1(69.7-89.0)^{\mathrm{a}}$ & $77.4(71.6-85.7)^{\mathrm{a}}$ & $77.9(72.8-83.5)^{a}$ \\
\hline$V_{200}(\%)$ & $41.4(28.1-75.9)$ & $41.8(27.2-53.6)$ & $42.5(30.3-50.4)$ & $40.9(32.7-48.5)$ \\
\hline No. needles used & $26(19-77)$ & $27(20-34)$ & $26(22-32)$ & $26(20-33)$ \\
\hline No. seeds used & $71(41-99)$ & $74(54-95)$ & $75(61-90)$ & $74(58-92)$ \\
\hline
\end{tabular}

PSA - prostate specific antigen, $D_{90}$-dose received by $90 \%$ of the prostate volume, $V_{100}(\%)$ - volume of prostate receiving $100 \%$ of the prescribed dose, $V_{150}(\%)$ percentage of prostate volume receiving $150 \%$ of the prescribed dose, $V_{200}(\%)$ - percentage of prostate volume receiving $200 \%$ of the prescribed dose asignificant to $p<0.05$ in ordinal model bsignificant to $p<0.001$ in ordinal model 
$6.1 \mathrm{ng} / \mathrm{ml}$; and median implant $\mathrm{V}_{150 \mathrm{~s}}$ were $76.2,77.1,77.4$, and $77.9 \%$, respectively. Other patient and treatment characteristics were not significantly different between groups (Table 2).

The ordinal model created had a Spearman's $\rho$ of 0.345 . Overall model likelihood ratio test showed a $p$-value of $<0.0001$ and individual factor analysis showed statistical significance in modeled variables. Figure 1 shows the cumulative probability distributions of this model for fixed median age, pre-treatment PSA, and $\mathrm{V}_{150}$. As can be seen here for a static median PSA of 5.8 and $V_{150}$ of 76.6, patients aged 40,50, 60, 70, and 80 have 4, 25, 55, 78, and $90 \%$ chances of having their 1yPSA be below 1.0, respectively. Similarly, for fixed age at 63.3 and $V_{150}$ of 76.6 , patients with pre-treatment PSAs of $0.1,0.5,1.0,2.0,3.0$, and 4.0 have $80,79,78,75,73$ and $69 \%$ chances of having their 1yPSA be below 1.0, respectively.

A

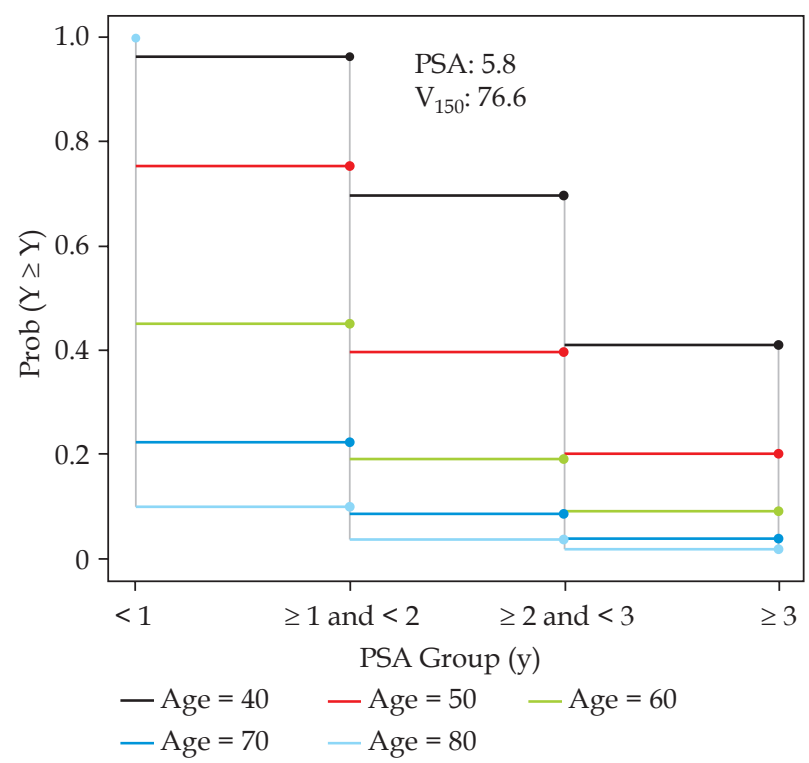

C

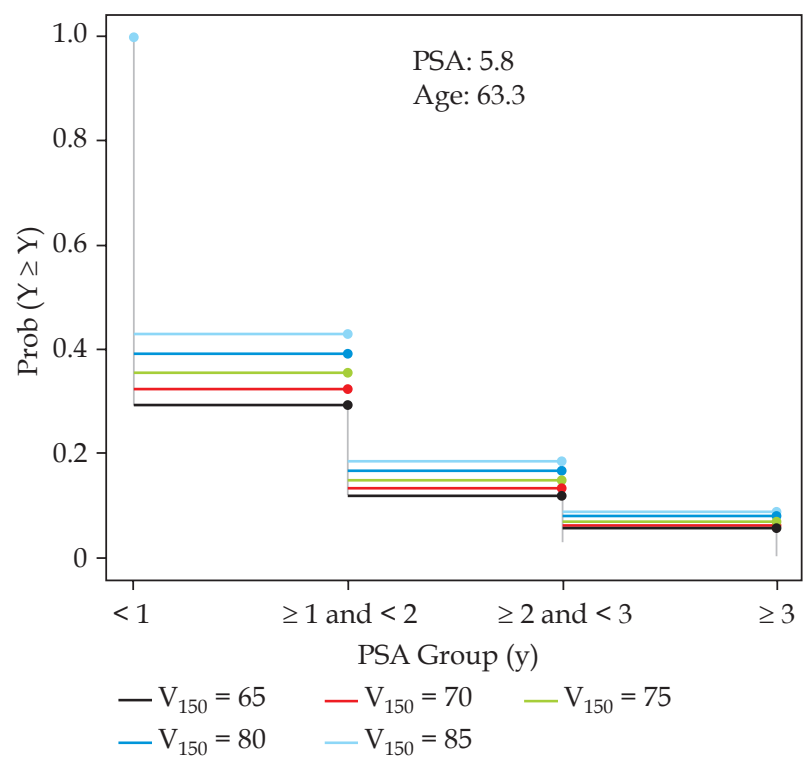

Thirty-five patients underwent procedures for prostate brachytherapy related complications. 13 procedures (9 cystoscopies and 3 transurethral resections of the prostate) were performed between 5.5 and 18.5 months of brachytherapy. Eight of these procedures were prior to their PSA measurement (6.4 to 3.6 months), and 4 were after (0.3-6.2 months). 1 patient required $>1$ week of catheterization during that time. Twenty-five patients $(6 \%$ of the cohort) required non-steroidal anti-inflammatories and/or alpha antagonists at the time of 1yPSA. 1yPSA values were not correlated with procedures, catheterization, and/or use of medication in the cohort (all $p$-values $>0.1$ ).

\section{Discussion}

Prediction of PSA decline in the first 12 months was possible in our cohort of patients treated with intraoper-

\section{B}

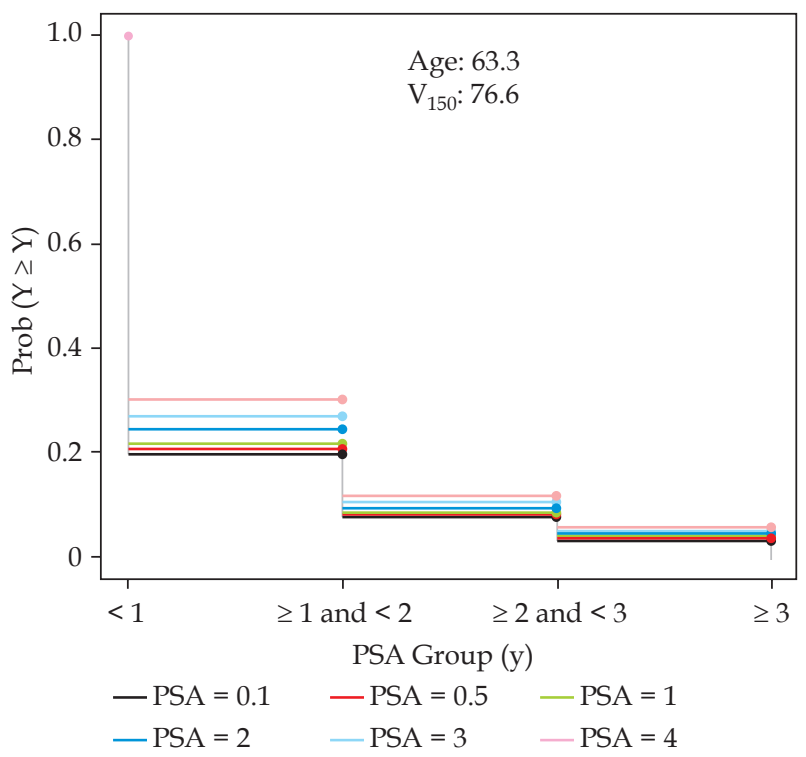

Fig. 1. Cumulative probability cross sections for 1yPSA groupings for varying A) age, B) initial PSA, and C) $\mathrm{V}_{150}$. Each plotted line represents the probability that a patient with the given variable characteristic (e.g., age 40 vs. 80) and static characteristics (e.g., initial PSA 5.8 and $V_{150}$ of 76.6) will have a final PSA in the given ordinal group or any higher group. Hence, there is always a $100 \%$ probability that a patient will be in group one or higher. However, as seen in our example, there are $96 \%$ and $10 \%$ chances that the 40 and 80 year old's will be in groups 2, 3, or 4 . Hence, there are $4 \%$ and $90 \%$ chances of 40 and 80 year old's having PSA $<1$. Plot A) fixed PSA of 5.8 and $V_{150}$ of 76.6. Plot $\mathbf{B}$ ) fixed $V_{150}$ of 76.6 and age of 63.3. Plot $C$ ) fixed initial PSA of 5.8 and age of 63.3 
atively planned brachytherapy. Specifically, older age, lower pre-treatment PSA, and lower implant $\mathrm{V}_{150}$ were found to be statistically significant predictors of enhanced PSA response.

Our analysis provides further insight into the analysis of PSA decline to nadir $<0.2 \mathrm{ng} / \mathrm{ml}$ by Critz. He found no correlation between length of time to meeting this goal and pretreatment PSA, clinical stage, and Gleason score [19]. Median times to nadir were 20 months for those without bounce, and 27 months for those with bounces in their cohort. Our data supports the conclusion that 1yPSA response is independent of clinical stage and Gleason scores. However, in the intraoperative setting, our results suggest a dependence of 1yPSA on pre-treatment PSA. There is a possibility that this effect is lost when considering lower absolute nadirs of PSA. Further to this study, we provide additional insight into factors which were not addressed, namely age and dosimetric parameters. As shown in Figures 2 and 3, we did find that 1yPSA showed correlation with time to this PSA nadir level.

One proposed mechanism for elderly patients having a faster decline in PSA post treatment is that they may have fewer cellular repair mechanisms, which leads to a faster rate of cell death post radiation induced DNA damage. This could theoretically leave less benign prostatic epithelium, and would be similar to the rationale proposed elsewhere for the tendency for younger patients to have benign bounces more frequently than their elder counterparts [20,21,22].

When considering the effects of $V_{150}$ on immediate response to therapy, it was noted that low $\mathrm{V}_{150 \mathrm{~s}}$ were associated with lower 1yPSA values. This could be explained by there being less acute inflammation of the prostate gland with smaller volumes receiving such large doses. At this point however, it is important to use caution in interpreting whether changes to accepted dosimetry should be made as the long-term effects of reducing dose/volumes are not addressed in this study.

Prediction of early PSA declines may be an important factor in future prostate brachytherapy follow-up. There is a growing body of evidence that even as early

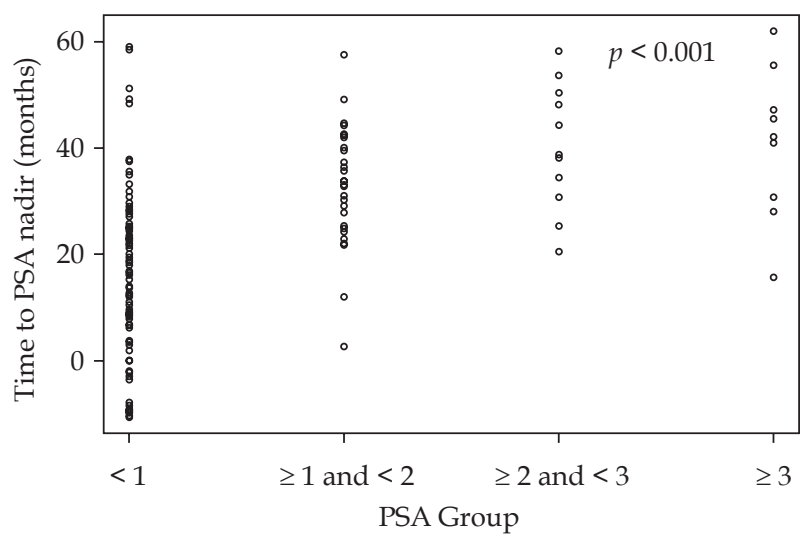

Fig 2. Time to PSA nadir $<0.2 \mathrm{ng} / \mathrm{ml}$ in months (from the time that the 1yPSA was measured) as a function of 1 yPSA grouping. Patients with PSA at 1 year $<1 \mathrm{ng} / \mathrm{ml}$ had significantly shorter times to nadir than all other patient groups

as 12 months post treatment PSA values are indicative of long-term response to treatment. For example, Ding et al. found that at 12 months post implant, the PSA value was predictive for long-term biochemical relapse free survival in their cohort [9]. They noted that patients who had PSA values < $1.0,<2.0,<3.0$, and $>3.0 \mathrm{ng} / \mathrm{ml}$ at 12 months post implantation had a 5 year PSA relapse free survival rates of $0.985,0.857,0.615$, and 0.222 , respectively. It was further noted that PSA levels $<1.0 \mathrm{ng} / \mathrm{ml}$ correlated with 10 year PSA relapse free survival rates of $90.5 \%$. Our cohort does not show this correlation $(p=0.33)$ but this analysis was underpowered, as only 87 patients had available PSA values at 5 years.

Furthermore, Ray et al. concur with these findings, and suggest that PSA nadir levels $<2.0 \mathrm{ng} / \mathrm{ml}$ results in biochemical disease free survival rates of $55 \%$ at 8 years [15]. Also, more recently Lo et al. published their results on PSA response to therapy at a median of 76 months post implantation [23]. They found that patients reaching PSA nadirs of $<0.2 \mathrm{ng} / \mathrm{ml}$ at this time had $<1 \%$ chance of subsequent recurrence.
A

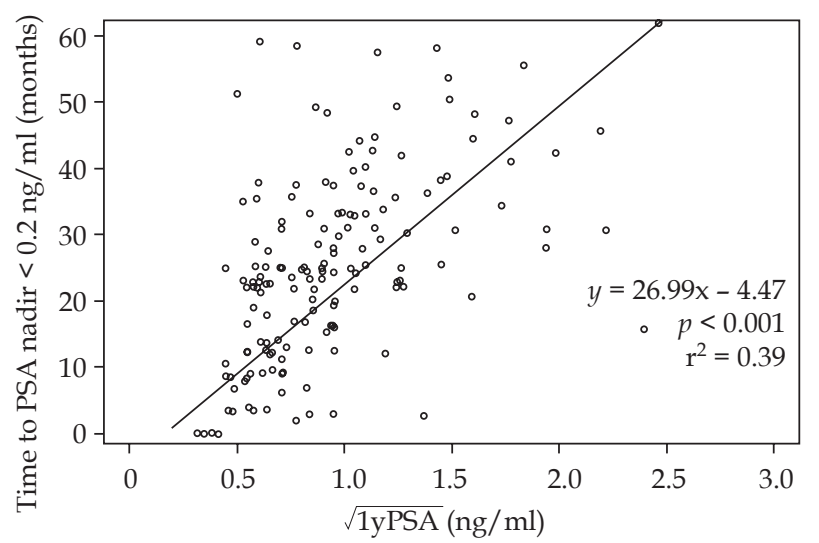

B

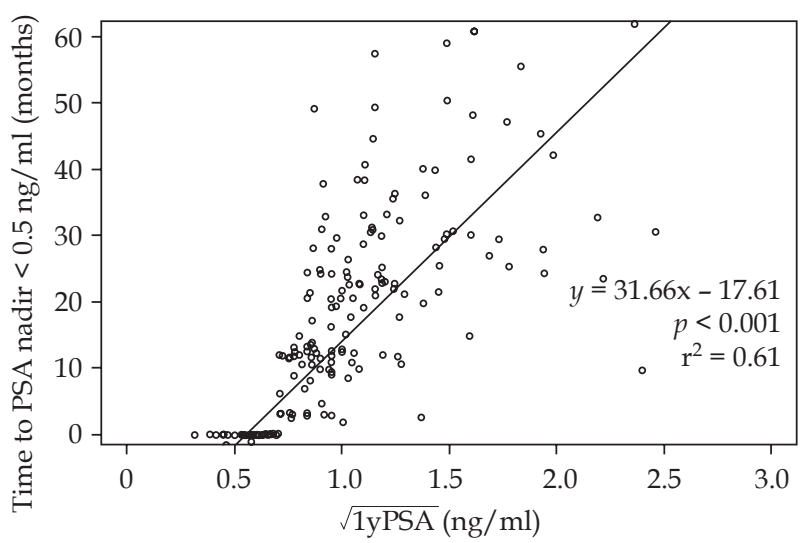

Fig. 3. Linearized regression modeling of relationship between 1yPSA and time to meet A) PSA nadir of < $0.2 \mathrm{ng} / \mathrm{ml}$, and B) PSA nadir of $<0.5 \mathrm{ng} / \mathrm{ml}$. These times are in months and are from the time of measurement of the 1yPSA 
When combined with our study, these suggest that a prediction algorithm for determining long-term response for patients based on information accrued shortly after prostate brachytherapy may indeed be possible. However, to date this has remained elusive. We do acknowledge that models do exist for estimation of survival $[24,25]$ after brachytherapy and prostatectomy but these fail to include any indicators of initial patient response to therapy or dosimetric parameters. Also, there may be other factors such as DNA ploidy and other conditions that affect dosimetry such as constipation, and seed displacement post implant, which need to be considered in any final model $[26,27,28]$.

When interpreting the results of this study, it is important to acknowledge that we are retrospectively analyzing this cohort of patients and inherent bias from unknown confounders is possible. Also, this analysis is on intra-operatively planned prostate brachytherapy implants and may not be transferable to the pre-operatively planned setting. Additionally, some patients with $>1.0 \mathrm{ng} / \mathrm{ml}$ 1yPSA may in fact be undergoing early PSA bounce phenomena [29]. This has been shown by Caloglu et al. to be associated with improved biochemical relapse free survival but only for PSA bounces of $<0.2 \mathrm{ng} / \mathrm{ml}$ [30]. Finally, the PSA assay used at our center had changed once over the study period.

\section{Conclusions}

Our study provides reassurance that treatment parameters other than biochemical failure are responsible for rate of PSA decline at 1 year post prostate brachytherapy. It is also an important first step in selecting patient cohorts for close monitoring and early determination of PSA relapse. When consideration is made for results published by other groups, it may be possible in the future to provide earlier interventions for those patients whose PSA declines are not behaving as predicted. We conclude that patients who are older, have lower pre-treatment PSA, and with lower implant $\mathrm{V}_{150}$, have lower $1 y$ PSA values.

We provide clinically useful cumulative probability distributions for prediction of early response to therapy, which may allow for physicians to better select patients who require more intensive follow-up.

\section{Disclosures}

Siraj Husain has received an unrestricted research grant from Elekta Incorporated for maintenance of the database. Kevin Martell has received travel funding support for presentation of this work at ESTRO-2015 from the University of Calgary. The authors have no other conflicts of interest or financial disclosures. All support for this project came as unrestricted funding. Specifically, Elekta had no access to data or influence on data collection, study design, or implementation.

\section{References}

1. Marshall R, Buckstein M, Stone N et al. Treatment outcomes and morbidity following definitive brachytherapy with or without external beam radiation for the treatment of local- ized prostate cancer: 20-year experience at Mount Sinai Medical Center. Urol Oncol 2014; 32: 38.e1-7.

2. Kupelian P, Potters L, Khuntia D et al. Radical prostatectomy, external beam radiotherapy $<72$ Gy, external beam radiotherapy $\geq 72$ Gy, permanent seed implantation, or combined seeds/external beam radiotherapy for stage T1-T2 prostate cancer. Int J Radiat Oncol Biol Phy 2004; 58: 25-33.

3. Tran AT, Mandall P, Swindell R et al. Biochemical outcomes for patients with intermediate risk prostate cancer treated with I-125 interstitial brachytherapy monotherapy. Radiother Oncol 2013; 109: 235-240.

4. Frank SJ, Levy LB, Van Vulpen M et al. Outcomes after prostate brachytherapy are even better than predicted. Cancer 2012; 118: 839-847.

5. Jabbari S, Weinberg VK, Shinohara K et al. Equivalent biochemical control and improved prostate-specific antigen nadir after permanent prostate seed implant brachytherapy versus high-dose three-dimensional conformal radiotherapy and high-dose conformal proton beam radiotherapy boost. Int J Radiat Oncol Biol Phys 2010; 76: 36-42.

6. Kaplan A, German L, Chen J et al. Validation and comparison of the two Kattan nomograms in patients with prostate cancer treated with (125) iodine brachytherapy. BJU Int 2012; 109: 1661-1665

7. Zhou P, Chen M-H, McLeod D et al. Predictors of prostate cancer-specific mortality after radical prostatectomy or radiation therapy. J Clin Oncol 2005; 23: 6992-6998.

8. Kuban D, Thames H, Levy L et al. Failure definition-dependent differences in outcome following radiation for localized prostate cancer: can one size fit all? Int J Radiat Oncol Biol Phys 2005; 61: 409-414.

9. Ding W, Lee J, Chamberlain D et al. Twelve-month prostate-specific antigen values and perineural invasion as strong independent prognostic variables of long-term biochemical outcome after prostate seed brachytherapy. Int J Radiat Oncol Biol Phys 2012; 84: 962-967.

10. Morris WJ, Pickles T, Keyes M et al. Pride or prejudice: does Phoenix flatter radiation therapy? Brachytherapy 2014; 13: 299-303.

11. Pickles T. Prostate-specific antigen (PSA) bounce and other fluctuations: which biochemical relapse definition is least prone to PSA false calls? An analysis of 2030 men treated for prostate cancer with external beam or brachytherapy with or without adjuvant androgen deprivation therapy. Int J Radiat Oncol Biol Phys 2006; 64: 1355-1359.

12. Caloglu M, Ciezki JP, Reddy C et al. PSA bounce and biochemical failure after brachytherapy for prostate cancer: a study of 820 patients with a minimum of 3 years of follow-up. Int J Radiat Oncol Biol Phys 2011; 80: 735-741.

13. Ciezki JP, Reddy C, Garcia J et al. PSA kinetics after prostate brachytherapy: PSA bounce phenomenon and its implications for PSA doubling time. Int J Radiat Oncol Biol Phys 2006; 64: 512-517.

14. Cheung R, Tucker SL, Kuban D. First-year PSA kinetics and minima after prostate cancer radiotherapy are predictive of overall survival. Int J Radiat Oncol Biol Phys 2006; 66: 20-24.

15. Ray ME, Levy LB, Horwitz EM et al. Nadir prostate-specific antigen within 12 months after radiotherapy predicts biochemical and distant failure. Urology 2006; 68: 1257-1262.

16. Nag S, Ciezki JP, Cormack R et al. Intraoperative planning and evaluation of permanent prostate brachytherapy: report of the American Brachytherapy Society. Int J Radiat Oncol Biol Phys 2001; 51: 1422-1430.

17. Beyer DC, Shapiro RH, Puente F. Real-time optimized intraoperative dosimetry for prostate brachytherapy: a pilot study. Int J Radiat Oncol Biol Phys 2000; 48: 1583-1589. 
18. Roach M 3rd, Hanks G, Thames H Jr et al. Defining biochemical failure following radiotherapy with or without hormonal therapy in men with clinically localized prostate cancer: recommendations of the RTOG-ASTRO Phoenix Consensus Conference. Int J Radiat Oncol Biol Phys 2006; 65: 965-974.

19. Critz FA. Time to achieve a prostate specific antigen nadir of $0.2 \mathrm{ng} / \mathrm{ml}$ after simultaneous irradiation for prostate cancer. J Urol 2002; 168: 2434-2438.

20. Thompson A, Keyes M, Pickles T et al. Evaluating the Phoenix definition of biochemical failure after (125)I prostate brachytherapy: Can PSA kinetics distinguish PSA failures from PSA bounces? Int J Radiat Oncol Biol Phys 2010; 78: 415-421.

21. Caloglu M, Ciezki J. Prostate-specific antigen bounce after prostate brachytherapy: review of a confusing phenomenon. Urology 2009; 74: 1183-1190.

22. Critz FA, Williams WH, Levinson AK et al. Prostate specific antigen bounce after simultaneous irradiation for prostate cancer: the relationship to patient age. J Urol 2003; 170: 1864-1867.

23. Lo AC, Morris WJ, Lapointe V et al. Prostate-specific antigen at 4 to 5 years after low-dose-rate prostate brachytherapy is a strong predictor of disease-free survival. Int J Radiat Oncol Biol Phys 2014; 88: 87-93.

24. Kattan MW, Potters L, Blasko JC et al. Pretreatment nomogram for predicting freedom from recurrence after permanent prostate brachytherapy in prostate cancer. Urology 2001; 58: 393-399.

25. Kattan MW, Wheeler TM, Scardino PT. Postoperative nomogram for disease recurrence after radical prostatectomy for prostate cancer. J Clin Oncol 1999; 17: 1499-1507.

26. Keyes M, Macaulay C, Hayes M et al. DNA ploidy measured on archived pretreatment biopsy material may correlate with prostate-specific antigen recurrence after prostate brachytherapy. Int I Radiat Oncol Biol Phys 2013; 86: 829-834.

27. Oton LF, Dolado MC, Nunez EJ et al. Effect of constipation on dosimetry after permanent seed brachytherapy for prostate cancer. J Contemp Brachytherapy 2015; 7: 247-251.

28. Wang Y, Nasser NJ, Borg J et al. Evaluation of the dosimetric impact of loss and displacement of seeds in prostate low-dose-rate brachytherapy. J Contemp Brachytherapy 2015; 7: 203-210

29. Wallner KE, Blasko J, Dattoli MJ. Prostate brachytherapy made complicated. Smart Medicine Press, Seattle 1997.

30. Caloglu M, Ciezki JP, Reddy CA et al. PSA bounce and biochemical failure after brachytherapy for prostate cancer A study of 820 patients with a minimum of 3 years of follow-up. Int J Radiat Oncol Biol Phys 2011; 80: 735-741. 